\title{
EA06
}

\section{Unveiling the Deep Secrets of the Mozambique} Channel

\author{
S. Raillard* (Total), J.N. Ferry (Total SA) \& J.F. Bourillet (Ifremer)
}

\section{SUMMARY}

Updating our geological concepts and turning them into meaningful tools to guide our exploration toward discoveries of new types of plays and new petroleum provinces is a major challenge for the oil \& gas industry. It demands to revisit our fundamentals (structural, sedimentary and fluids) and start over with a geodynamic approach to the formation of sedimentary basins.

Staying abreast of advances in academic research is paramount as we strive to formulate these innovative concepts and predict new plays. Total strategy is to stay poised to detect and quickly take up the most innovative scientific ideas and pass them on to the field in real time. This will be the key to successful frontier exploration. 


\section{Introduction}

Updating our geological concepts and turning them into meaningful tools to guide our exploration toward discoveries of new types of plays and new petroleum provinces is a major challenge for the oil $\&$ gas industry. It demands to revisit our fundamentals (structural, sedimentary and fluids) and start over with a geodynamic approach to the formation of sedimentary basins.

Staying abreast of advances in academic research is paramount as we strive to formulate these innovative concepts and predict new plays. Total strategy is to stay poised to detect and quickly take up the most innovative scientific ideas and pass them on to the field in real time. This will be the key to successful frontier exploration.

In 2013, Total and Ifremer in collaboration with Universities and Ifpen, have launched an ambitious R\&D partnerships aiming to develop a multidisciplinary approach of continental margins through the multi-years PAMELA R\&D program (Passive Margin Exploration Laboratories).

\section{Method and/or Theory}

The Mozambique Channel has been selected as one of our natural laboratory, dedicated to understand extensional and transform continental margins evolution from their rifting processes to their present day configuration.

This area has started as a complex transform margin, which resulted in the separation of Madagascar from the rest of Africa and generated various types of margin segments (oblique, pure transform, passive, volcanic...etc...) as well as several highly different sedimentary basins.

It's post-rift and drift evolution has undergone several severe volcanic stages starting as soon as late Lower Cretaceous to Recent time, modifying and impacting the sedimentary basin infilling.

However, the area has been poorly studied since the late 70's, and necessitate a strong acquisition program to improve its understanding.

Between 2014 and 2018, Ifremer's vessels will complete a set of more than 7 data acquisition campaigns across the Mozambique Channel. Geophysical acquisition, sampling (coring, dredging), sea bottom detailed mapping, long offset seismic but also fluid escape related biological sampling will provide new data allowing an holistic approach of the East African continental margins evolution and their related terrigeneous and carbonated sedimentary basins.

The deep crust structure investigation coupled with standard tectono-sedimentary studies will allow to precisely define the geological, stratigraphical and tectonic calendars. The wells drilled by Total in the early 70's will be studied using updated technology on core and cuttings. This will allow an up-todate calibration of this evolution.

Moreover, ambitious onshore campaigns will be realized on both Mozambique and Madagascar sedimentary basins. The objective will be to identify and quantify the major uplift stages affecting East Africa and Madagascar and to define the amount and nature of rocks eroded.

Their transfer to the offshore domain will be analyzed thanks to the seismic and well data available in the basins. A particular focus will be made on the recent evolution of the Zambeze deep-sea canyon and valley and its interactions with the deep-sea current.

Finally, some deep offshore areas have been selected in order to complete this approach through seafloor investigation to detect sediment instabilities, fluids escape and biological colonies associated with. 


\section{EAGE}

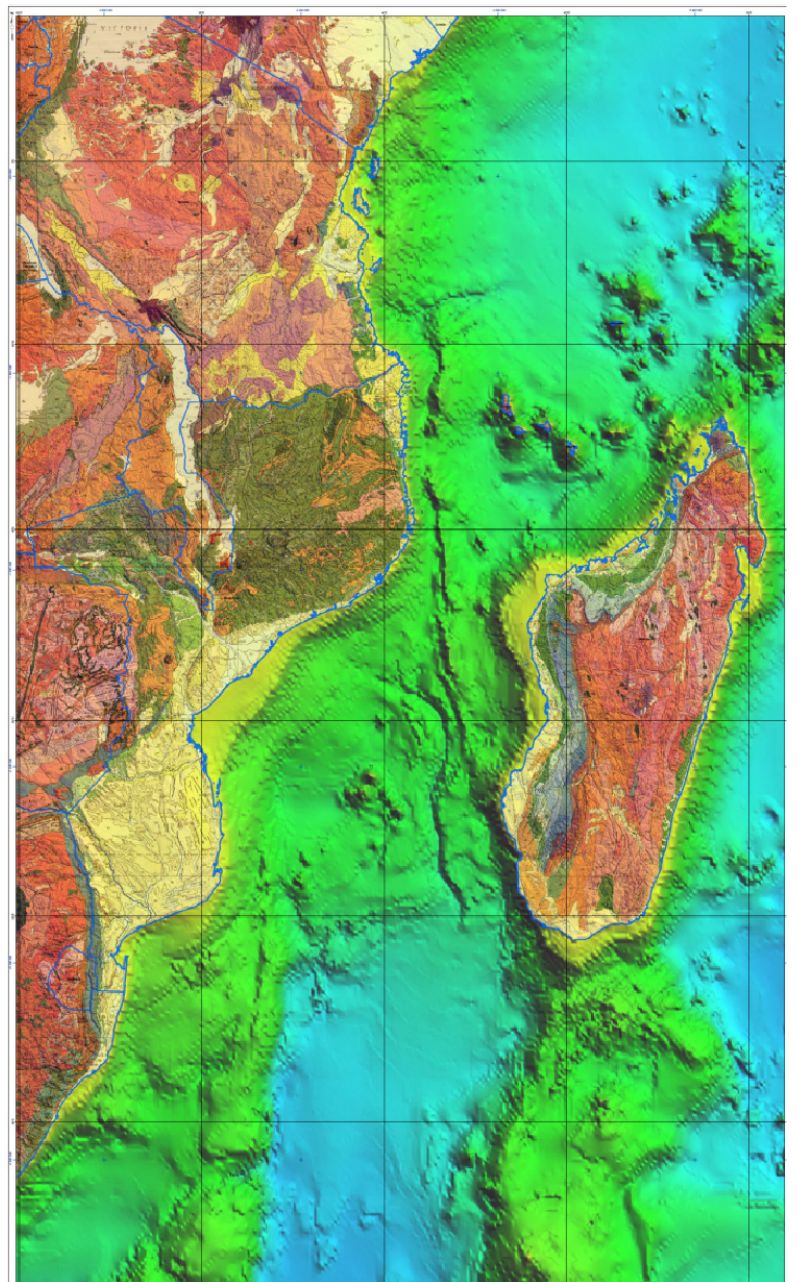

Figure 1 The East African Margins and the Mozambique Channel Bathymetric Map.

\section{Conclusions}

This will allow a global understanding of the relationships between deep geodynamics, sedimentary basin histories and surface processes in the area of the Mozambique Channel.

The objectives of the collaboration is also, through an open R\&D philosophy, to melt researcher from different scientific domains such as geodynamics, geomorphology, sedimentology, structural geology, biology, sea-floor hazards, fluids specialists on a same laboratory in order to maximize opportunities to generate new geological concepts. 